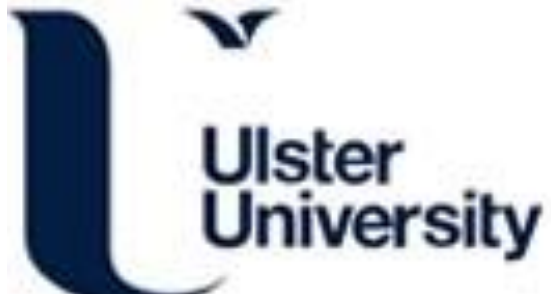

\section{Antibacterial properties of sophorolipid-modified gold surfaces against Gram positive and Gram negative pathogens.}

\author{
Valotteau, C., Banat, I., Mitchell, C., Lydon, H., Marchant, R., Babonneau, F., Pradier, C-M., Baccile, N., \& \\ Humblot, V. (2017). Antibacterial properties of sophorolipid-modified gold surfaces against Gram positive and \\ Gram negative pathogens. Colloids and Surfaces B: Biointerfaces, 157, 325-334. \\ https://doi.org/10.1016/j.colsurfb.2017.05.072
}

Link to publication record in Ulster University Research Portal

Published in:

Colloids and Surfaces B: Biointerfaces

Publication Status:

Published online: 02/06/2017

DOI:

10.1016/j.colsurfb.2017.05.072

\section{Document Version}

Author Accepted version

\section{General rights}

Copyright for the publications made accessible via Ulster University's Research Portal is retained by the author(s) and / or other copyright owners and it is a condition of accessing these publications that users recognise and abide by the legal requirements associated with these rights.

\section{Take down policy}

The Research Portal is Ulster University's institutional repository that provides access to Ulster's research outputs. Every effort has been made to ensure that content in the Research Portal does not infringe any person's rights, or applicable UK laws. If you discover content in the Research Portal that you believe breaches copyright or violates any law, please contact pure-support@ulster.ac.uk. 


\section{Accepted Manuscript}

Title: Antibacterial properties of sophorolipid-modified gold surfaces against Gram positive and Gram negative pathogens

Authors: Claire Valotteau, Ibrahim M. Banat, Christopher A. Mitchell, Helen Lydon, Roger Marchant, Florence Babonneau, Claire-Marie Pradier, Niki Baccile, Vincent Humblot

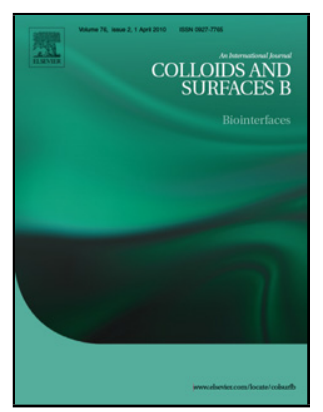

PII:

DOI:

Reference:

S0927-7765(17)30340-5

http://dx.doi.org/doi:10.1016/j.colsurfb.2017.05.072

COLSUB 8601

To appear in: $\quad$ Colloids and Surfaces B: Biointerfaces

Received date: $\quad 10-1-2017$

Revised date: 21-4-2017

Accepted date: $\quad$ 29-5-2017

Please cite this article as: Claire Valotteau, Ibrahim M.Banat, Christopher A.Mitchell, Helen Lydon, Roger Marchant, Florence Babonneau, Claire-Marie Pradier, Niki Baccile, Vincent Humblot, Antibacterial properties of sophorolipid-modified gold surfaces against Gram positive and Gram negative pathogens, Colloids and Surfaces B: Biointerfaceshttp://dx.doi.org/10.1016/j.colsurfb.2017.05.072

This is a PDF file of an unedited manuscript that has been accepted for publication. As a service to our customers we are providing this early version of the manuscript. The manuscript will undergo copyediting, typesetting, and review of the resulting proof before it is published in its final form. Please note that during the production process errors may be discovered which could affect the content, and all legal disclaimers that apply to the journal pertain. 


\section{Antibacterial properties of sophorolipid-modified gold surfaces}

\section{against Gram positive and Gram negative pathogens}

Claire Valotteau, ${ }^{1,2}$ Ibrahim M. Banat, ${ }^{3}$ Christopher A. Mitchell, ${ }^{3}$ Helen Lydon, ${ }^{3}$, Roger Marchant ${ }^{3}$, Florence Babonneau, ${ }^{1}$ Claire-Marie Pradier, ${ }^{2}$ Niki Baccile, ${ }^{1, *}$ Vincent Humblot ${ }^{2, *}$ 1 Sorbonne Universités, UPMC Univ Paris 06, CNRS, Collège de France, Laboratoire de Chimie de la Matière Condensée de Paris, UMR 7574, 4, Place Jussieu, 75005 Paris, France.

2 Sorbonne Universités, UPMC Univ Paris 06, CNRS, Laboratoire de Réactivité de Surface, UMR 7197, 4 place Jussieu, 75005 Paris, France.

3 School of Biomedical Sciences, Ulster University, Coleraine, BT52 1SA, UK

*Corresponding vincent.humblot@upmc.fr and niki.baccile@upmc.fr

Graphical Abstract

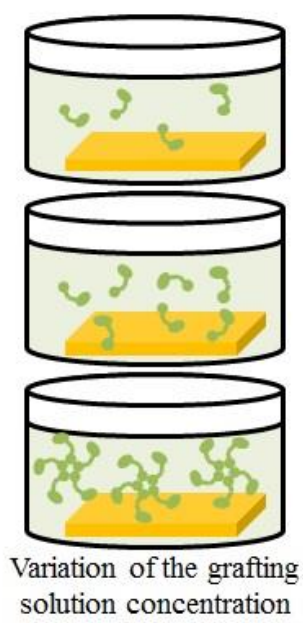

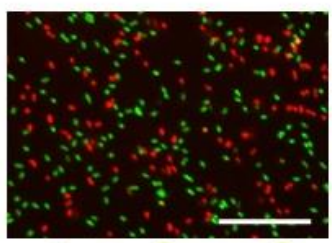

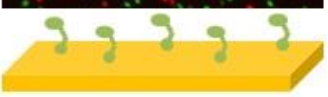

Exploration of sophorolipid-grafted model surfaces reactivity
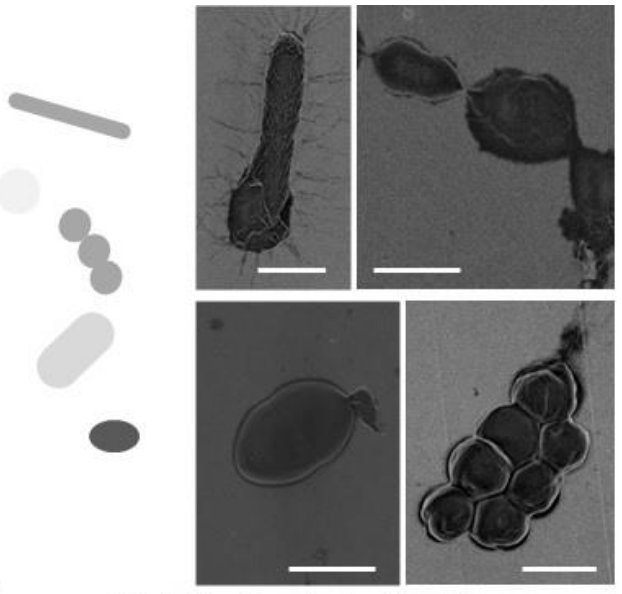

Test of various bacterial strains

\section{Highlights}

- Successful Adsorption of Sophorolipids on gold surfaces at various concentrations.

- $\bullet$

- The initial concentration of Sophorolipids solutions affects the amount of grafted molecules monitored by XPS and QCM-D.

$\bullet$

- The biocidal activity was monitored by contact of bacterial strains on the coated substrates compared to bare surfaces.

- Sophorolipid-modified gold surfaces are biologically active against Gram positive and Gram negative pathogens

\section{ABSTRACT}

Sophorolipids are bioderived glycolipids displaying interesting antimicrobial properties. We show that they can be used to develop biocidal monolayers against Listeria ivanovii, a 
Gram-positive bacterium. The present work points out the dependence between the surface density and the antibacterial activity of grafted sophorolipids. It also emphasizes the broad spectrum of activity of these coatings, demonstrating their potential against both Gram-positive strains (Enteroccocus faecalis, Staphylococcus epidermidis, Streptococcus pyogenes) and Gram-negative strains (Escherichia coli, Pseudomonas aeruginosa and Salmonella typhymurium). After exposure to sophorolipids grafted onto gold, all these bacterial strains show a significant reduction in viability resulting from membrane damage as evidenced by fluorescent labelling and SEM-FEG analysis.

Keywords: Sophorolipid; self-assembled monolayers; antibacterial surface; membranedamaging activity

\section{INTRODUCTION}

Carbohydrates are an interesting group of functional compounds with a variety of properties and applications in pharmacology (vaccines, drugs) 1,2,3 and diagnosis (glycomicroarrays for antibody recognition and cell adhesion). 4 Their use as antimicrobials is of particular interest, with glycolipids or polysaccharides having broad activities for prevention of microbial contamination either via antiadhesive or biocidal properties.5 For instance, amphotericin B6 a complex glycolipid, is a commonly employed antifungal, while exopolysaccharides7 are used for their antiadhesive properties. Other bioderived glycolipids like rhamnolipids, cellobioselipids or sophorolipids8 are well-known for their antimicrobial properties. Their biocidal effect seems to depend on the synergistic effect of the sugar and lipid moieties in the so-called "surfactant-effect", $8,9,10$ which is characterized by plasma membrane disruption, causing lysis and possible leakage of cytoplasm material.11,12 Antiadhesive properties are also commonly observed for polysaccharides and glycolipids which are either immobilized on a substrate (glycoarray) or free in solution. $5^{, 13,14}$

The antimicrobial effects of carbohydrate-based compounds are worth studying because of their mild/low cytotoxicity and low ecotoxicological effects and their lower cost (compared to other antimicrobial agents like peptides) 15 which make them very appealing for large scale application, such as protection of outdoor infrastructure for instance. Moreover the diversity in this carbohydrate family promotes a broad spectrum of activity.16. Despite these advantages and the extensive use of these compounds as antimicrobial agents, the role of the carbohydrate moiety, and in particular its interaction with the cell envelope is still not very clear. The interactions between carbohydrates and bacterial membranes have been studied for decades 17 . However, only recently, modeling studies have tried to put in evidence the impact of simple mono and disaccharides on the liquid crystalline order of phospholipid bilayers, 18 although in 
vitro data are still lacking. In our recent work, we have shown for the first time that a selfassembled monolayer (SAM) composed of glucose $\beta 1,2$ glycolipid stabilized on gold is able to pierce the cell envelope, and in particular the plasma membrane, of the non-pathogenic bacterial strain Listeria ivanovii.19 This work has shown the important membrane-disrupting role of the disaccharide, which cannot be related to the so-called "surfactant-effect"since the glycolipid is covalently bond to the surface. However, we showed the impact of the disaccharide orientation on the efficiency of bacterial membrane disruption.

In the present work, we studied the effect of glycolipid grafting density on its biocidal properties. Indeed, sugar concentration appears as a key factor in sugar-membrane interactions 20 and grafting may enable to reach high concentrations in the vicinity of bacteria, thus enhancing its antimicrobial effects3; we also want to explore the spectrum of activity of such grafting towards several Gram positive and Gram negative bacterial strains.

\section{MATERIALS AND METHODS}

Cysteamine (cys), N-hydroxysuccinimide (NHS), 1-(3-(dimethylamino)propyl)-Nethylcarbodiimide hydrochloride (EDC), glutaraldehyde and sodium chloride $(\mathrm{NaCl})$ were obtained from Sigma-Aldrich (Saint Quentin Fallavier, France). Sophorolipids (SL) were derived from a commercial acidic and lactone mixture of sophorolipids purchased from Soliance (France) (Sopholiance S; batch number, 11103A; dry content, $60 \pm 6 \%$ ). To obtain a high purity form of the nonacetylated acidic sophorolipids only (>90 mol \%, according to ${ }^{1} \mathrm{H}$ NMR analysis), classical hydrolysis was performed using $5 \mathrm{M} \mathrm{NaOH}$ followed by acidification by $\mathrm{HCl}$ and pentanol extraction. 21

All solvents were reagent-grade and were used without any further purification. Water was purified with a Milli-Q system (Millipore, resistivity $>18 \mathrm{M} \Omega \mathrm{cm}^{-1}$ ) from EMD Millipore Corp. (Billerica, MA).

Glass substrates, coated successively with a $50 \AA$ thick layer of chromium and a $200 \mathrm{~nm}$ thick layer of gold, were purchased from Arrandee (Werther, Germany).

\section{Surface Preparation}

The substrates have been prepared using a standard protocol detailed in ref.20. To ensure a good crystallinity of the gold top layer, the substrates were annealed in a butane flame and afterwards exposed to UV-ozone during $15 \mathrm{~min}$. Substrates were then immersed in an ethanolic solution of cys at $10 \mathrm{mM}$ for $3 \mathrm{~h}$. Sonication in ultrapure ethanol was carried out during $5 \mathrm{~min}$ to desorb the non-grafted molecules and samples were then rinsed successively in ethanol and in ultrapure water before being dried under a flow of dried air. 
The carboxylic acid termination of SL was activated by succinimide ester using a mixture of EDC and NHS (molar ratio NHS:EDC $=1: 2$ ) in water to further react with the SAM amine group and form a covalent bond. Three concentrations of SL were used: $5 \mathrm{mg} . \mathrm{L}^{-1}, 50 \mathrm{mg} . \mathrm{L}^{-1}$ and $500 \mathrm{mg} . \mathrm{L}^{-1}$; the substrates were immersed for $3 \mathrm{~h}$ in one of these solutions. Sonication and successive rinsing in ultrapure water and ethanol were carried out to remove non-covalently grafted reactants before drying under a flow of dried air. All samples were characterized by infrared spectroscopy after each step of functionalization.

Quartz Crystal Microbalance with Dissipation (QCM-D)

The QCM-D measurements were performed in liquid phase using Q-Sense E1 device from Qsense (Sweden). The crystal used was a thin AT-cut gold-coated quartz provided by Q-Sense (Sweden) grafted with cysteamine as previously described for gold samples. Oscillations of the crystal at the resonant frequency $(5 \mathrm{MHz})$ and its overtones $(15,25,35,45,55$ and $65 \mathrm{MHz})$ were obtained by applying AC voltage. The temperature was maintained at $22,0 \pm 0,1^{\circ} \mathrm{C}$. The liquid cell was connected to a peristaltic pump (Ismated IPC-N 4) and the flow rate was fixed to $100 \mu \mathrm{L} / \mathrm{min}$. Ultrapure water was first injected to avoid any perturbation in frequency due to the medium change when SL solution was injected. Each solution (SL solution and then ultrapure water for rinsing) was brought into the measurement cell until stationary frequency and dissipation signals were obtained. Shifts of frequency $(\Delta f)$ and dissipation $(\Delta \mathrm{D})$ were recorded for the resonance frequency and the first 5 overtones. Frequency shifts $\Delta \mathrm{f}_{\mathrm{n}}$ measured at overtone $n$ were renormalized to the fundamental frequency value by dividing $\Delta \mathrm{f}_{\mathrm{n}}$ by $n$. The data presented in this article correspond to the third overtone.

$X$-ray Photoelectron Spectroscopy (XPS)

XPS analyses were performed using an Omicron Argus X-ray photoelectron spectrometer. The monochromated $\mathrm{AlK}_{\alpha}$ radiation source $(h v=1486.6 \mathrm{eV})$ had a $300 \mathrm{~W}$ electron beam power. The emission of photoelectrons from the sample was analyzed at a takeoff angle of $90^{\circ}$ under ultrahigh vacuum conditions ( $\leq 10^{-10}$ Torr). Spectra were carried out with a $100 \mathrm{eV}$ pass energy for the survey scan and $20 \mathrm{eV}$ pass energy for the $\mathrm{C} 1 \mathrm{~s}, \mathrm{O} 1 \mathrm{~s}, \mathrm{~N} 1 \mathrm{~s}, \mathrm{~S} 2 \mathrm{p}$ regions. Binding energies were calibrated against the $\mathrm{Au} 4 \mathrm{f}_{7 / 2}$ binding energy at $84.0 \mathrm{eV}$ and element peak intensities were corrected by Scofield factors 22 . The peak areas were determined after subtraction of a linear background. The spectra were fitted using Casa XPS v.2.3.15 software (Casa Software Ltd., U.K.) and applying a Gaussian/Lorentzian ratio G/L equal to 70/30.

Observation of Bacterial Morphology by Scanning Electron Microscopy.

Qualitative analysis of the bacterial morphology was carried out by mean of scanning electron microscopy, which enables one to visualize the effect of antimicrobial products on bacteria and 
could help to identify general target sites23. Since observations are done under vacuum, samples were previously fixed with $2.5 \%$ glutaraldehyde in phosphate buffer saline $(\mathrm{pH}=7.4)$ to avoid collapsing of structures. Samples were then fixed on an alumina SEM support with a carbon adhesive tape and observed without metallization. SEM images were recorded with a Hitachi SU-70 field emission gun scanning electron microscope, using an in-lens secondary electron detector ( $\mathrm{SE}_{\mathrm{Upper}}$ ). The accelerating voltage was $1 \mathrm{kV}$ and the working distance was around $5 \mathrm{~mm}$. At least five different locations were analyzed on each surface (observation of a minimum of 100 single bacteria).

\section{Antimicrobial Activity. Strains and Culture Conditions}

The antibacterial properties of the modified surfaces were tested against four Gram positive and three Gram negative bacteria strains (see Table 1). Bacteria were cultivated overnight in their nutrient broth at $37{ }^{\circ} \mathrm{C}$ under agitation $(250 \mathrm{rpm})$. The cells from stationary cultures were harvested by centrifugation at $10,000 \mathrm{~g}$ for $5 \mathrm{~min}$ and dispersed in an isotonic sterile solution $(\mathrm{NaCl} 0.9 \%)$. The optical density of the broth was controlled at $620 \mathrm{~nm}$ and adjusted at 0.05 , which corresponds to approximately $5 \times 10^{6}$ colony forming unities (CFU) per $\mathrm{mL}$.

\section{Deposition of Bacteria on Samples}

Each sample was sterilized by immersion in a solution of $70 \%$ ethanol (in water) and dried in a sterile environment. Surfaces were then inoculated with a $100 \mu \mathrm{L}$ drop of bacterial suspension and incubated for $3 \mathrm{~h}$ at room temperature in a wet atmosphere. After incubation, surfaces were washed five times with $100 \mu \mathrm{L}$ of isotonic sterile solution $(\mathrm{NaCl} 0.9 \%)$ to remove all nonadhering bacteria.

\section{Evaluation of Bacteria Adhesion by Infrared Spectroscopy}

Samples were dried under a laminar airflow. Each surface was scanned by PM-RAIRS to collect the signal from all the adhered bacteria. PM-RAIRS measurements were performed using a Nicolet Nexus 5700 FT-IR spectrometer equipped with a nitrogen-cooled $\mathrm{HgCdTe}$ wide band detector. Infrared spectra were recorded at $8 \mathrm{~cm}^{-1}$ resolution, by coaddition of 128 scans. A ZnSe grid polarizer and a ZnSephotoelastic modulator were placed prior to the sample in order to modulate the incident beam between $\mathrm{p}$ and s polarizations (HINDS Instruments, PM90, modulation frequency $=36 \mathrm{kHz}$ ). The sum and difference interferograms were processed and underwent Fourier-transformation to yield the PM-RAIRS signal which is the differential reflectivity $\left(\Delta \mathrm{R} / \mathrm{R}^{0}\right)=(\mathrm{Rp}-\mathrm{Rs}) /(\mathrm{Rp}+\mathrm{Rs})$. All measurements (on bare gold and functionalized surfaces) were performed during the same experimental session, thus reducing at minimum intensity variations of the background, beam intensity and alignment. The relative amounts of 
bacteria adsorbed were evaluated by considering the amide I and II bands area between 1700 and $1500 \mathrm{~cm}^{-1}$.

The attachment of bacteria onto the different surfaces is expressed as a percentage compared to gold substrates: Adhesion $(\%)=100 \times$ (area of amide bands on sample) $/($ area of amide bands on gold). The uncertainty attached to this percentage comes from the propagation of the uncertainties attached to the measurement of amide bands area on both the considered surface and the gold substrate (standard deviation SD observed considering 3 independent experiments) on both the considered surface and the gold substrate, ie $\Delta$ Adhesion $(\%)=$ $\sqrt{ }\left(\left[100 \times \mathrm{SD}_{\text {sample }} /(\text { area of amide bands on gold) }]^{2}+\left[100 \times \mathrm{SD}_{\text {gold }} \mathrm{x}\right.\right.\right.$ (area of amide bands on samples $\left.\left.) /(\text { area of amide bands on gold })^{2}\right]^{2}\right)$. These results were confirmed by repeating the same procedure on three different sets of samples.

\section{Evaluation of Bacteria Damaging by Fluorescent Staining}

The Live/Dead Bacterial Viability Kit (BacLight $\left.{ }^{\circledR}\right)$ enables the counting bacteria with damaged membranes. A $10 \mu \mathrm{L}$ volume of a fluorochrome solution was prepared by mixing $1.5 \mu \mathrm{L}$ of Syto9 stain and $1.5 \mu \mathrm{L}$ of propidium iodide (PI) with $1 \mathrm{~mL}$ of ultrapure water, which was deposited on the inoculated surface of each sample after rinsing. Samples were then incubated in dark for 10 min prior to microscopic analysis. Surfaces were kept in a humid environment during the experiments to prevent drying. Samples were examined with an epifluorescence microscope (AXIO 100 Zeiss), images acquired with a $10 \times$ or $40 \times$ objective lens and subsequently recorded with a CCD camera (AxioCamMRm Zeiss). Fluorochromes were, respectively, excited and detected at 455-495 $\mathrm{nm}$ and 505-555 $\mathrm{nm}$ (for Syto9) and at 533-558 $\mathrm{nm}$ and 570-640 nm (for PI). About 10 different locations of each surface were analyzed and at least a thousand bacteria were enumerated in order to attain statistically relevant data; experiments were repeated on three sets of samples. Bacterial counting (red, damaged membrane; green, intact membrane) was done using the software ImageJ and the viability calculated as follows: Viability $(\%)=100 \times($ number of green bacteria) $/($ number of green bacteria + number of red bacteria).

\section{Cultivability (bacterialgrowth capacity)}

The bacterial growth capacity after being in contact with the samples was evaluated as follows: inoculated surfaces were transferred into a sterile tube containing $2 \mathrm{~mL}$ of isotonic sterile solution $(\mathrm{NaCl}$ at $0.9 \%)$ and sonicated $5 \mathrm{~min}$. The gold sample was removed and bacteria suspensions were diluted 10, 100 and 1000 times. A volume of $50 \mu \mathrm{L}$ of each dilution was deposited in duplicate on Petri dishes filled with nutrient agar $(15 \mathrm{~g} / \mathrm{L})$. The plates were incubated at $37^{\circ} \mathrm{C}$ overnight before enumeration. Results are expressed in percentages of the number of attached and cultivable bacterial cells onto the different surfaces as compared to gold substrates: Cultivability $(\%)=100 \times($ number of colonies forming unity on sample $) /($ number of 
colonies forming unity on bare gold substrate). These tests were done in triplicate on each type of samples and the cultivability value was averaged over the three samples. The uncertainty attached to these results follows from the statistical analysis of these repeated experiments.

\section{RESULTS AND DISCUSSION}

\section{Variation of SL grafting density}

In order to explore the effect of glycolipid grafting density on biocidal properties, gold surfaces were functionalized with solutions at different sophorolipid concentrations. The first step was to assess the possible influence of the initial concentration on the modification of gold surfaces. The lowest concentration used was $5 \mathrm{mg} . \mathrm{L}^{-1}, \mathrm{ca} .0 .8 \mu \mathrm{mol} . \mathrm{L}^{-1}$; at this concentration, the solution contains theoretically enough molecules to fully saturate the surfaces with SL molecules (ca. $5 \times 10^{15}$ molecules in the $10 \mathrm{~mL}$ volume in which 2 gold samples of $1 \mathrm{~cm}^{2}$ are immersed) with respect to the number of available amino-thiols adsorbed in the SAM (number previously estimated to be $4 \times 10^{14}$ molecules per $\left.\mathrm{cm}^{2}\right) .{ }^{19}$ In addition, solutions at concentrations 10 and 100 times higher $(50 \mathrm{mg} / \mathrm{L}$ and $500 \mathrm{mg} / \mathrm{L})$ were also tested.

QCM-D results

Quartz crystals coated with gold, were functionalized ex situ with cysteamine following the protocol applied for plain gold surfaces and were then submitted to a flow of activated sophorolipid solution within the QCM cell. Changes in the resonant frequency $(\Delta \mathrm{f})$ and dissipation $(\Delta \mathrm{D})$ are shown in Figure 1. The most concentrated solution $\left(\mathrm{C}=500 \mathrm{mg} \cdot \mathrm{L}^{-1}\right)$ resulted in very different variation features compared to those observed with the dilute solutions $\left(\mathrm{C}=5\right.$ and $\left.50 \mathrm{mg} \cdot \mathrm{L}^{-1}\right)$. These differences suggest that the mode of formation and characteristics of the sophorolipids adlayers differ.

As shown by Figure 1, the injection of dilute solutions of sophorolipids ( $\mathrm{C}=5 \mathrm{mg} . \mathrm{L}^{-1}$ and $\left.50 \mathrm{mg} . \mathrm{L}^{-1}\right)$ caused a variation of the resonance frequency while the dissipation remains stable $\left(\Delta \mathrm{D}<0.6 \times 10^{-6}\right)$, which is characteristic of the adsorption of small molecules and the formation of rigid layers. The change in frequency increased with the concentration of sophorolipids: after injection of sophorolipid solutions, $\Delta \mathrm{f}$ decreased and stabilized at a value of $-3.6 \mathrm{~Hz}$ for the lowest concentration $\left(\mathrm{C}=5 \mathrm{mg} \cdot \mathrm{L}^{-1}\right)$, and around $-13 \mathrm{~Hz}$ for the medium concentration $\left(\mathrm{C}=50 \mathrm{mg} . \mathrm{L}^{-1}\right)$. In the first case $\left(\mathrm{C}=5 \mathrm{mg} . \mathrm{L}^{-1}\right)$, the frequency variation remained almost stable during the rinsing step; on the contrary, $\Delta \mathrm{f}$ varied in the second case $\left(\mathrm{C}=50 \mathrm{mg} . \mathrm{L}^{-1}\right)$ and stabilized at a value of $\sim-9 \mathrm{~Hz}$. This latter increase was a sign that some sophorolipids molecules were weakly adsorbed to the surface, and that the rinsing step evacuated these noncovalently bond molecules. 
Using Sauerbrey's equation which is valid in liquid for homogeneous non-viscous films, i.e. for $\Delta \mathrm{D} / \Delta \mathrm{f}<<10^{-7}, 24$ like in the case of initial SL concentrations of 5 and $50 \mathrm{mg} / \mathrm{L}$, one can evaluate the mass change on the surface: $\Delta m=-C_{f}^{*} \Delta f_{n} / n$, where $C_{f}$ is the mass sensitivity. Thus the mass of sophorolipids adsorbed on the surface after surface treatment with sophorolipid solutions and rinsing with the corresponding solvent is estimated to be $\sim 70 \mathrm{ng}^{\mathrm{cm}}{ }^{-2}$ (or $\sim 0.7 \times 10^{14}$ molecules.cm $\left.{ }^{-2}\right)$ in the case of the most dilute solution $\left(\mathrm{C}=5 \mathrm{mg} . \mathrm{L}^{-1}\right)$, and $\sim 180 \mathrm{ng} . \mathrm{cm}^{-2}\left(\sim 2 \times 10^{14}\right.$ molecules. $\left.\mathrm{cm}^{-2}\right)$ in the case of the intermediate concentration $\left(\mathrm{C}=50 \mathrm{mg} \cdot \mathrm{L}^{-1}\right)$. These measurements suggest therefore that the final amount of sophorolipids covalently bound to the surface depends on the initial concentration of sophorolipids in solution. Considering the estimated grafted density of cysteamine thiols previously obtained by XPS $\left(\sim 4 \times 10^{14} \text { molecules.cm }{ }^{-2}\right)^{19}$, and taking into account that a $100 \%$ SL coverage would be obtained for each cys molecule having reacted with one SL molecule, the ratio of sophorolipids grafted is evaluated to $\sim 17 \%$ and $\sim 45 \%$ for the surfaces prepared with solutions concentration of $5 \mathrm{mg} . \mathrm{L}^{-1}$ and $50 \mathrm{mg} . \mathrm{L}^{-1}$, respectively. It is important to note that these percentages are not a rate of reaction with respect to the amount of molecules present in the grafting solution, but yet the amount of actual grafted SL molecules compared to the possible maximum amount of graftable SL molecules, with respect to the available anchoring point and molecular sticking coefficient. The latter grafting rate (45\%) should correspond to a dense layer of SL molecules, forming a saturated monolayer. Indeed, in an adlayer with a grafting density of $45 \%$ above thiols layer, each oleic acid molecule should cover roughly an area of 30-35 $\AA^{2}$; knowing that the interfacial area between sophorose and oleic acid was estimated to be around $70 \AA^{2}$ in micelles 25 , this indicates that sophorolipids should be closely packed on grafted layers. These results have to be considered with caution since they are based on data acquired in very different conditions (ultra-high vacuum and dried ex situ conditions for XPS data, in opposition to liquid phase in situ conditions for QCM data), but they are, nevertheless, very informative on the formation process of such layers.

The phenomena observed during the injection of the most concentrated solution $\left(\mathrm{C}=500 \mathrm{mg}\right.$. $\mathrm{L}^{-}$ ${ }^{1}$ ), were very different, $C f$. Figure 1 ; the frequency variation profile is much more abrupt $(\Delta \mathrm{f}$ drops to $-11.8 \mathrm{~Hz}$ within minutes before stabilizing, while at lower concentration the stabilization occurs after 1hour) and this drop is accompanied by a drastic change in the dissipation $\left(\Delta \mathrm{D}\right.$ close to $\left.2 \times 10^{-6}\right)$. The rinsing step causes some fast variations both for the frequency and dissipation measurements: the frequency increased and $\Delta \mathrm{f}$ stabilized at about $6.4 \mathrm{~Hz}$ while the dissipation decreased until $\Delta \mathrm{D}$ reached $\sim 0.8 \times 10^{-6}$ (Figure 1, left). These values 
are typical of viscoelastic layers and/or highly hydrated films for which it is difficult to assess the deposited mass.

Behavior of adsorbed sophorolipids thus differs significantly when the concentration of solution varies; evolution of $\Delta \mathrm{D}$ versus $\Delta \mathrm{f}_{\mathrm{n}} / \mathrm{n}$ during the injection of the sophorolipids solution, shown on the right-hand side of Figure 1, provides direct information on the energy dissipated as a function of the adsorbed mass at the surface. This type of representation, $\Delta \mathrm{D}=f\left(\Delta \mathrm{f}_{\mathrm{n}} / \mathrm{n}\right)$, is particularly used to study the adsorption mechanisms of enzymes.26, 27 This adsorption often takes place in two stages28: a first phase, extremely fast as indicated by disperse data points close to the axes origin, is attributed to the direct adhesion of enzymes on surfaces, and a second phase, much slower indicated by the densification of the data-point cloud, is due to structural rearrangements of the adsorption phase processes (conformational changes caused by enzymes/surfaces and enzymes/enzymes interactions, reorganization of the supramolecular layer, changes in the hydration of the layer). ${ }^{26}$

Similarly, adsorption at the solid-liquid interface of surfactants, such as sophorolipds, can be described as a 2 steps-process involving first the transportation of molecules from the liquid phase to a stagnant phase adjacent to the surface and then the transfer of molecules from the subsurface onto the surface.29 Similar variations were observed following the injection of the concentrated solution of sophorolipids $\left(\mathrm{C}=500 \mathrm{mg} . \mathrm{L}^{-1}\right)$; in this case, the frequency varies rapidly and then stabilizes as the dissipation increases (the rinsing step is not considered here). It is thus possible to imagine that the adsorption of molecules on the surface is followed by a phase of reorganization and/or hydration of the formed layer. However, in the latter case, an increase in the hydration rate would be accompanied by a further decrease in the frequency, which was not the case here (Figure 1, left). Therefore, here it is more likely that the second step of the process was mainly a reorganization of the adlayer.

Conversely, the injection of more diluted solutions of sophorolipids ( $\mathrm{C}=5$ and $\left.50 \mathrm{mg} . \mathrm{L}^{-1}\right)$ seems to lead to a single homogeneous rigid layer. It is interesting to note that these different phenomena (adsorption followed by a phase of reorganization vs. uniform adsorption) were observed for concentrations located either side of the critical micelle concentration $(\mathrm{cmc})$ of non succinimide-activated acidic sophorolipids, which is about $100 \mathrm{mg} \cdot \mathrm{L}^{-1} \cdot 30^{, 31}$ This is consistent with previous studies that highlight three distinct regimes for surfactant adsorption isotherms:32 low adsorption occurs in the case of diluted solutions and increases significantly with concentration, finally reaching up a pseudo plateau. The inflection point separating these two regimes (high adsorption and pseudo-plateau) is the critical micelle concentration, while the transition between the low adsorption regime and the increasing adsorption regime occurs 
at concentrations of about $10 \%$ of the critical micelle concentration. Additional works focused on the QCM-D characterization of ionic surfactants on gold and silica also confirm that significant dissipation is only measured for bulk surfactant concentrations above the $\mathrm{cmc}$, while negligible dissipation is observed for bulk concentrations below the $\mathrm{cmc}: 33^{, 34}$ the generallyaccepted hypothesis is that below the $\mathrm{cmc}$, the surfactant adsorbs in a single monolayer, while above the cmc, a self-assembled phase, the nature of which depends on the molecular structure of the surfactant, ${ }^{34}$ adds to the first monolayer.Thus, the surfactant nature of sophorolipid molecules should strongly influence their interaction with surfaces, accordingly with what is known from the literature of surfactant adsorption on rigid substrates, the only difference being that, in the system described here, the first sophorolipid monolayer is chemisorbed (and not simply physisorbed) onto the cysteamine primer due to the amidation reaction between succinimide activated-SL and $\mathrm{NH}_{2}$.

XPS analyses

Surfaces prepared using solutions at different sophorolipid concentrations were also analyzed by XPS to confirm the surface chemistry and to estimate the relative amounts of the various elements constituting the adlayers, as well as the surface coverage,and compare these data with those obtained by QCM.

High resolution S2p, C1s, O1s and N1s spectra were thus recorded before and after immersion into sophorolipid solutions. Figure 2 displays the $\mathrm{C} 1 \mathrm{~s}$ and N1s regions, while S2p and O1s data can be found in supplementary section (Figure S1).

On the $\mathrm{C} 1 \mathrm{~s}$ spectrum recorded on the thiol cysteine layers (Au-cys), one can see the presence of two main peaks attesting the presence of aliphatic carbon atoms $(284.8 \pm 0.1 \mathrm{eV})$ and carbon atoms in $\mathrm{C}-\mathrm{S}$ and $\mathrm{C}-\mathrm{N}$ bonds at $286.5 \pm 0.1 \mathrm{eV}$. The N1s region shows two contributions, at $399.9 \pm 0.1 \mathrm{eV}$ and $401.8 \pm 0.1 \mathrm{eV}$, ascribed respectively to $\mathrm{NH}_{2}$ and $\mathrm{NH}_{3}{ }^{+}$. XPS spectra thus confirm the grafting of cysteamine with $\mathrm{NH}_{2} / \mathrm{NH}_{3}{ }^{+}$terminal groups available for the further step of functionalization 35 .

After grafting sophorolipid (Au-cys-SL) the decomposition of the carbon C1s XPS spectrum of sophorolipid showed 4 contributions (Figure 2A). The most intense, at $284.8 \pm 0.1 \mathrm{eV}$ was due to the carbons of the aliphatic chain. The peaks at $286.4 \pm 0.1 \mathrm{eV}$ and $287.7 \pm 0.1 \mathrm{eV}$ were attributed to the carbon linked to oxygen in the sophorose unit ( $\mathrm{C}-\mathrm{OH}$ and $\mathrm{O}-\mathrm{C}-\mathrm{O}$ respectively). Finally the band at $289.0 \pm 0.1 \mathrm{eV}$ was attributed to $\mathrm{C}=\mathrm{O}$ of the carboxylic acid and/or amide bond.36 These four contributions are visible on all surfaces after immersion in sophorolipid solutions. The signature of the disaccharide moieties at $286.4 \pm 0.1 \mathrm{eV}$ is particularly noticeable on surfaces prepared with the most concentrated solution $\left(\mathrm{C}=500 \mathrm{mg} \cdot \mathrm{L}^{-1}\right)$; these latest surfaces 
would therefore be coated with a larger amount of sophorolipids. On the contrary, the spectrum obtained for the surfaces grafted with the most dilute SL solution $\left(\mathrm{C}=5 \mathrm{mg} . \mathrm{L}^{-1}\right)$ appears almost unchanged after immersion compared to the original spectrum of the cysteamine-functionalized surface(Au-cys). Nevertheless one can notice the appearance of a small contribution at $289.0 \pm 0.1 \mathrm{eV}$, characteristic of $\mathrm{C}=\mathrm{O}$ bonds of amide groups, suggesting that a small amount of SL is grafted on the surface.

These results are corroborated by the analysis of XPS spectra of nitrogen, shown in Figure $2 \mathrm{~B}$. No significant change was visible after immersion in the most dilute solution $\left(\mathrm{C}=5 \mathrm{mg} . \mathrm{L}^{-1}\right)$ but after immersion in the concentrated SL solutions $\left(C=50\right.$ and $\left.500 \mathrm{mg} . \mathrm{L}^{-1}\right)$ the contribution of $\mathrm{NH}_{3}{ }^{+}$groups at $401.8 \pm 0.1 \mathrm{eV}$ decreases in favor of the peak at $399.9 \pm 0.1 \mathrm{eV}$ assigned to $\mathrm{NH}_{2}$ amine and $\mathrm{NH}$ amide. This shift suggests the formation of amide bonds between cysteamine and succinimide activated-SL. However amines and amides have the same binding energy $(399.9 \pm 0.1 \mathrm{eV})$ and therefore the elemental nitrogen analysis can't confirm by its own the covalent grafting of SL on the surface. Therefore, S2p and O1s XPS regions were also investigated; results for O1s are shown in supplementary section, Figure S1.

At the first glance, XPS spectra suggest that the amount of grafted sophorolipids is lower on samples prepared with the most dilute solution $\left(C=5 \mathrm{mg} . \mathrm{L}^{-1}\right)$, when considering the ratios of carbon and gold signal intensities (Table S1). The atomic composition of the different surfaces could be estimated more accurately by considering the intensity of the various XPS signals; these data are summarized in Table S2. After immersion of surfaces into SL solutions, the percentages of nitrogen and sulfur decrease as a function of increasing solutions concentration. However, since the same atoms are present before and after SL grafting, analyses of elementary composition remain difficult. An alternative to estimate the quantity of added material is to calculate the thickness of organic layers formed on the metal surfaces. The thickness of an assumed homogeneous layer on the sample surface can be assessed by considering the XPS signal of a layer component and that of the substrate; the detailed calculations are explained in details elsewhere $^{19}$ (see equation $\mathrm{S} 1$ in supplementary information). Here it is possible to consider as typical of the adlayer the signal from the $\mathrm{C}=\mathrm{O}$ (ie. the $\mathrm{C} 1 \mathrm{~s}$ contribution at $289.0 \mathrm{eV}$ ) or the signal from N-H amide binding the thiol SAM and the grafted SL molecules(ie. the N1s whole region centered at $400.0 \mathrm{eV}$ ). Alternatively, one can also use the $\mathrm{S} 2 \mathrm{p}$ signal to calculate the total average thickness of the organic adlayers (including the thiol layer and the molecules added on top); these estimations are summarized in Table 2.

One can see that at a given concentration of SL solution all three methods of calculation give the same approximation of the average thickness. This parameter is correlated to the density 
and considering that a SL molecule occupies an incompressible volume, we should expect that a higher number of molecules per area leads to a higher thickness. Indeed samples prepared with a SL solution at a medium concentration $\left(50 \mathrm{mg} . \mathrm{L}^{-1}\right)$ appear slightly thicker than the ones prepared with a more dilute solution $\left(5 \mathrm{mg} . \mathrm{L}^{-1}\right)$, the density of the latter being lower according to the QCM analyses ( 0.7 molecule/nm² vs. 2 molecules $/ \mathrm{nm}^{2}$ for a sample prepared with a solution at $\left.50 \mathrm{mg} . \mathrm{L}^{-1}\right)$. Besides, the thickness of the adlayer appears almost identical for samples immersed into the most dilute and the most concentrated solutions $\left(5 \mathrm{mg} . \mathrm{L}^{-1}\right.$ and $500 \mathrm{mg} . \mathrm{L}^{-1}$ respectively). This similarity is surprising at the first glance: since QCM data suggest that micelles or bilayers are adsorbed when concentrated solution are used, one could expect to detect a thicker layer in such case. Nevertheless, it should be kept in mind that a raw comparison of data obtained in situ (by QCM) and ex situ (by XPS) is not strictly possible, and that it should be done carefully, taking into accounts as many assumptions as possible. Indeed, XPS data were recorded after drying the surface and under vacuum, so the complex architecture of adsorbed multilayers may have been destroyed in such conditions (it is known that upon drying the SL (or any other organic layer) will "collapse" on itself), leaving on the surface only a partial layer, maybe not as dense as a well-organized and fully-packed monolayer. Consequently, both QCM and XPS analyses suggest that the amount of grafted SL varies according to the initial concentration of the grafting SL solution. The use of a solution at a moderate concentration (50 mg. $\mathrm{L}^{-1}$ ) enables to form the densest and fully-packed layer of SL onto surfaces.

\section{Influence of grafting density to antimicrobial activity}

In order to assess the antimicrobial effect of the above prepared and characterized sophorolipidmodified surfaces (Au-cys-SL), a set of antimicrobial assays was carried out employing Listeria ivanovii, a Gram-positive bacterium. The detailed protocols are presented in the experimental section.The following tests are systematically performed: 1) direct observation of the plasma membrane integrity using the staining Live/Dead ${ }^{\odot}$ kit in combination with fluorescence microscopy (bicolor bars, red and green for dead and alive respectively); 2) bacterial adhesion tests measured from IR data (sum of red and green bars) and 3) cultivability tests (grey bars). The data are normalized by the data obtained on biocompatible gold surfaces and compared to the sophorolipid-free control constituted by the primer-modified gold substrate (Au-cys).

The results displayed in Figure 3 together with the corresponding values in Table S3 show that the antimicrobial effect is small on surfaces prepared with the most dilute sophorolipid solution $\left(\mathrm{C}=5 \mathrm{mg} . \mathrm{L}^{-1}\right)$ but increases on samples conditioned with the more concentrated solutions $\left(\mathrm{C}=50\right.$ and $\left.500 \mathrm{mg} . \mathrm{L}^{-1}\right)$ on which almost half of the bacteria are altered. Physico-chemical characterizations of these surfaces suggest that the amount of SL-grafted increases with the 
concentration of the grafting solution. Taken together, these results evidence a dose-dependent effect of grafted-SL: their biocidal activity is linked to their local density. Such dependence was already highlighted for biocidal cationic surfaces for which exists a threshold of charge-density for optimum efficiency $37^{38}$. More generally, the surface density of biomolecules is known to influence the recognition and interaction phenomena at the biointerfaces 39 , while studies on microarrays have demonstrated density-dependent binding preferences of carbohydrate-binding proteins. 40 High densities could also lead to the establishment of multivalent bindings and then enhance the effect of glyconanomaterials.41 Concentration also appears as a key factor for membrane-sugar interactions in solution ${ }^{20}$ : at low concentration, sugars directly interact with the lipid bilayer and their accumulation at the interface makes the membrane thinner and laterally expanded. At high concentrations however, sugars are expelled from the hydration zone and exert an indirect effect on the membrane via a local osmotic imbalance and concomitant increase in interfacial free energy. Here there was no clue to suggest whether the surface concentrations lead to one or the other phenomenon but the outstanding correlation between green and grey bars evidences that the membrane damages induced by sophorolipids lead to a loss of bacterial cultivability and is consistent with the suggestion that the antibacterial effect is achieved via membrane destabilization.

As the antimicrobial effect is more prevalent on surfaces prepared with concentrated solutions (C = 50 and $500 \mathrm{mg} / \mathrm{L}$ ), coupled to the perturbation observed by QCM-D for the $500 \mathrm{mg} / \mathrm{L}$ solution, we have chosen $50 \mathrm{mg} / \mathrm{L}$ as initial SL solution concentration to explore the effect of sophorolipids on different bacterial strains.

\section{Spectrum of Au-grafted-SL antimicrobial activities}

The antimicrobial potential of SL-grafted surfaces was examined on both Gram-positive bacteria (Enterococcus faecalis (Ef), Staphylococcus epidermidis (Se), Streptococcus pyogenes $(S p))$ and Gram-negative bacteria (Escherichia coli $(E c)$, Pseudomonas aeruginosa $(P a)$, Salmonella typhimurium (St)).The results of microbial tests performed on Au-cys and Au-cysSL surfaces are summarized in Figure 4 with corresponding values on Table S4.

In Figure 4, adhesion (bicolor bars) on the control thiol surface (Au-cys) varies significantly according to the bacterial strain; between $120 \%$ (E. coli, P. aeruginosa) and $103 \%$ (S. pyogenes) indicating that some strains adhere more to the Au-cys surfaces than to gold. In addition, the bicolor bars indicate that the fraction of damaged bacteria (red portion) remains low and the gap between intact bacteria (green portion) and cultivable bacteria (grey bars) practically falls within the range of the error bars. 
As far as the adhesion properties of the sophorolipid-modified surfaces (Au-cys-SL) are concerned (bicolor bars), there is no specific adhesive/antiadhesive effect for any of the bacterial strains tested, as the average value was always around $100 \%$ with respect to gold, as highlighted in a previous study ${ }^{19}$. However, a significant percentage of these bacteria has lost their membrane integrity (red portion of the bicolors bars on the adhesion scale) and a reduction of growth capacity was observed with all strains: the percentages of cultivability (grey bars) varied between $55 \%$ and $80 \%$, thus indicating that between $20 \%$ and $45 \%$ of the microorganism population was not viable after being in contact with grafted sophorolipids. The most affected strain was the Gram-positive Staphylococcus epidermidis, while the Gramnegative Salmonella typhimurium was the least affected. In the Gram-negative organisms we tested, the percentage viability was consistent $(\sim 70 \%)$, indicating that SL have no specific interactions with bacterial membranes. Contrastingly, in $\mathrm{Gram}^{+}$bacteria, this effect varied as a function of the strain (from 55 to $75 \%$ ), suggesting that the bactericidal mode of action of SL may be linked to the specific composition of the outer membrane of some strains of $\mathrm{Gram}^{+}$ bacteria.

The aforementioned data are also supported by ultrastructural examination of the bacterial membrane following exposure to the Au-cys \pm SL substrate. As shown in Figure 5, all bacteria have regular surface morphology when in contact with the Au-cys control substrate, while the morphology is altered in some organisms after contact with the sophorolipid-modified substrates (Au-cys-SL). The end-tips of diplococci of Enterococcus faecalis exhibit protuberances suggesting a leak of the intracellular content 42,19 . Similarly, the clusters formed by Staphylococcus epidermidis appear shriveled, while individual organisms within the chains of Streptococcus pyogenes demonstrate a range of sizes and irregular shapes, which is sometimes associated with dispersion of intracellular content; all damages are pointed by white arrows in Figure 5. Similar size and shape alterations in morphology have been reported for the Gram $^{+}$Listeria ivanovii upon contact with biosurfactants or carbohydrates. ${ }^{11,19}$ Pinched or collapsed cell walls are also evident in the $\mathrm{Gram}^{-}$bacterial strains examined: these were most conspicuous in Escherichia coli, but were also observed to a lesser extent in Salmonella typhimurium and Pseudomonas aeruginosa contaminated surfaces.

These data supports the conclusion that sophorolipid-modified gold surfaces are able to affect the integrity of a variety of both $\mathrm{Gram}^{+}$and $\mathrm{Gram}^{-}$bacterial strains; although we provide qualitative and quantitative data indicating that $\mathrm{Gram}^{+}$are more affected than $\mathrm{Gram}^{-}$strains. Our data are corroborated at several scales, using fluorescent staining and cultivating bacteria 
after exposure to the surface, and at the ultrastructural level, using scanning electron microscopy.

The cell envelope of $\mathrm{Gram}^{-}$bacteria is more complex than the one of $\mathrm{Gram}^{+}$bacteria, as it is composed of an outer lipopolysaccharide and phospholipid outer membrane prior to the peptidoglycan layer and inner plasma membrane. Although some glycolipids, such as rhamnolipid or even sophorolipids themselves ${ }^{11}$, are known to cause changes in outer membrane proteins of $\mathrm{Gram}^{-}$bacteria (Pseudomonas aerugionsa)43, the models of cell lysis are often focused on the destabilization of the inner membrane and tend to neglect the variation of physico-chemical properties within the cell envelope. Nevertheless the interactions with the outer membrane rely on distinct mechanisms, as demonstrated for antimicrobial peptide polymyxin B1.44 This antimicrobial compound also destabilizes the inner membrane core, by insertion and concomitant increased hydration, but their insertion within the outer membrane appears to be a much more complex process. Moreover, in our case, sophorolipids were not free in solution but grafted onto an $\mathrm{Au}$ surface and the cell envelope is several tens of nanometers thickness (much thicker than the typical size of a sophorolipid layer, which, according to XPS, does not go beyond $3 \mathrm{~nm}$ ). As we previously argued, the destabilizing effect of Au surface-grafted sophorolipids cannot be explained by a direct interaction with the plasma membrane, although we showed that the bacterial membrane was damaged (i.e. fluorescence experiments in Figure 4). One must then consider other mechanisms of destabilization, as we have previously proposed, ${ }^{19}$ and in particular either sugar-protein/sugar-sugar mediated destabilization interactions of the lipid bilayer or a potential impact of the sugar group on the biochemical reactions occurring at the cell envelope/medium interface.

\section{CONCLUSION}

In a recent publication we have shown that a monolayer of sophorolipids, microbial-derived glycolipids, can be chemically grafted on top of a gold substrate using a cysteamine primer and that such a material exhibits antibacterial properties against Listeria ivanovii, a non-pathogenic $\mathrm{Gram}^{+}$bacterium. In this work, we go further and show that gold substrates engineered to tether modified-sophorolipids also damage the membrane of a series of pathogenic $\mathrm{Gram}^{+}$ (Enterococcus faecalis, Staphylococcus epidermidis, Streptococcus pyogenes) and Gram (Escherichia coli, Pseudomonas aeruginosa, Salmonella typhimurium) bacteria. Using a combination of QCM-D and XPS we found that the optimal concentration of SL on the surface which forms a homogeneous, stable monolayer is $50 \mathrm{mg} . \mathrm{L}^{-1}$. Between $20 \%$ and $45 \%$ of each of the bacterial populations we studied have a damaged membrane, as revealed by fluorescent staining. This result is corroborated by additional measurements of growth capacity on agar 
plates after exposure to Au tethered sophorolipid-modified substrates. Meanwhile, all control surfaces constituted by the primer (cysteamine)-modified gold do not reveal a significant impact on the bacterial population (no membrane damage and no decrease of cultivability). From a mechanistic point of view, these results show that the sophorose head group is able to damage both $\mathrm{Gram}^{+}$and $\mathrm{Gram}^{-}$bacterial envelopes, even though $\mathrm{Gram}^{-}$bacteria have an additional outer lipid membrane and lipopolysaccharide layer. Thus, these data confirm that of our earlier work in which the biocidal effect of the sophorolipid layer (whose thickness is less than $5 \mathrm{~nm}$ ) cannot be explained by a direct perturbation of the cytoplasmic membrane (inner membrane of the cell envelope whose thickness is of several tens of nanometers) ${ }^{19}$. From an applicative point of view, we show that these SL-grafted surfaces can affect strains, which are pathogenic in humans, thus increasing the interest in developing, understanding and improvement in the biocidal efficiency of these materials.

\section{ACKNOWLEDGMENTS}

The authors would like to acknowledge the French state funds managed by the ANR within the Investissementsd'Avenir program under Reference ANR-11-IDEX-0004-02 and more specifically withinthe framework of the Cluster of Excellence MATISSE for a Ph.D. Grant for CV.The authors acknowledge IMPC (Institut des Matériaux deParis Centre, FR2482) and the C' Nano projects of the RegionIle-de-France, for SEM-FEG and Omicron XPS apparatusfunding. The authors would also like to thank Dr. SouhirBoujday from LRS lab for her help during QCM experiments and analyses of the data. Finally, the authors would like to acknowledge S. Casale for performing some of the SEM-FEG recording. 


\section{References}

\section{References}

1 H. M., Evans P. G., Gemmell N., Osborne S. D. Carbohydrate-Based Therapeutics. J. Pharm. Pharmacol. 2004, 56, 691-702.

2 A., Jimenez-Barbero J., Casnati A., De Castro C., Darbre T., Fieschi F ., Finne J., Funken H., Jaeger K.-E., Lahmann M., Lindhorst M., Marradi M., Messner P., MolinaroA., Murphy P.V., Nativi C., Oscaron S., Penades S., Peri F., Pieters R.J., Renaudet O., Reymond J.-L., Richichi B., Rojo J., Sansone F., Schaffer C., Turnbull W.B., Velasco-Torrijos T., Vidal S., Vincent S., Wennekes T., Zhuilhof, Imberty A. Multivalent glycoconjugates as antipathogenic agents. Chem. Soc. Rev. 2013, 42 (11), 4709-4727.

3 O., Yan M. Glyconanomaterials for combating bacterial infections. Chem. Eur J. 2015, 21 (46), 16310-16317.

4 N., Voglmeir J., Flitsch S. L. Glycoarrays -Tools for Determining Protein-Carbohydrate Interactions and Glycoenzyme Specificity. Chem. Commun. 2008, 4400-12.

5 A. d. J., Hernandez-Sanchez H., Jaramillo-Flores M. E. Biological Activity of Glycolipids Produced by Microorganisms: New Trends and Possible Therapeutic Alternatives. Microbiol. Res. 2013, 168, 22-32.

6 J., Powderly W. G., Kobayashi G. S., Medoff G. Amphotericin B: Current Understanding of Mechanisms of Action. Antimicrob. Agents Chemother. 1990, 34, 183-188.

7 J., Da Re S., Henry N., Fontaine T., Balestrino D., Latour-Lambert P., Ghigo J. M. Broad-Spectrum Biofilm Inhibition by a Secreted Bacterial Polysaccharide. Proc. Natl. Acad. Sci. U. S. A. 2006, 103, 12558-12563.

8 S., Katsiwela E., Wagner F. Antimicrobial Effects of Biosurfactants. Fett/Lipid. 1989, 91, 363-366.

9 Chapman J., Diehl M., Lyman R. Biocide Susceptibility and Intracellular Glutathione in Escherichia Coli. J. Ind. Microbiol. 1993, 12, 403-407.

10 R. E., Smith R. R., Jones M. V., Jackson S. K., Rowlands, C. C. An Epr Investigation of Surfactant Action on Bacterial Membranes. FEMS Microbiol. Let. 1999, 177, 57-62.

11 E., Baskunov B., Zvonarev A. The antibiotic and membrane-damaging activites of cellobiose lipid and sophorose lipids. Journal of Oleo Science. 2014, 63 (7), 701-707.

12 Zhang X, Fan X., Solaiman D. K. Y., Ashby R. D., Liu Z., Mukhopadhyay S., Yan R., Inactivation of Escherichia coli O157:H7 in vitro and on the surface of spinach leaves by biobased antimicrobial surfactants Food Control, 2016, 60, 158-165

13 P., Llamas M. A. Promising Biotechnological Applications of Antibiofilm Exopolysaccharides. Microb. Biotechnol. 2012, 5, 670-673.

14 Diaz De Rienzo M.A., Dolman B., Guzman F., Kaisermann C., Winterburn J., Banat I.M., Martin P. Antimicrobial properties of sophorolipids produced by Candida Bombicola ATCC 22214 against gram positive and Gram-negative bacteria. New Biotechnology 2014 31: S66-S67

15 Banat I.M., Franzetti A., Gandolfi I., Bestetti G., Martinoti M.G., Fracchia L., Smyth T.J., Marchant R. Microbial biosurfactants production, applications and future potential. Applied Microbiology and Biotechnology. 2010, 87 (2), 427-444.

16 De Rienzo M.A., Banat I.M.,Dolman B., Winterburn J., Martin P.J. Sophorolipid biosurfactants: Possible uses as antibacterial and antibiofilm agent. New Biotechnology, 201532 (6):720-726. .

17 F.A. Carbohydrate-binding proteins: tertiary structures and protein-sugar interactions. Ann Rev Biochem. $1986,55,287-315$.

18 G., Lopez C.A., Bartelds R., Syga L., Rijpkema E., Cukkemane A., et al. Disaccharides impact the lateral organization of lipid membranes. Journal of the American Chemical Society. 2014, 136, 16167-16175 
19 C., Calers C., Casale S., Berton J., Stevens C.V., Babonneau F., Pradier C.-M., Humblot V., Baccile N. Biocidal Properties of a Glycosylated Surface: Sophorolipids on Au(111). ACS Appl. Mater. Interf. 2015, 7, 18086-18095.

20 H. D., Wang C., Arleth L., Peters G.H., Westh P. PNAS, 2011, 108 (5), 1874-1878.

21 N., Cuvier A.-S., Valotteau C., Van Bogaert I. N. A. Practical Methods to Reduce Impurities for Gram-Scale Amounts of Acidic Sophorolipid Biosurfactants. Eur. J. Lipid Sci. Technol. 2013, 115, 1404-1412.

22 Scofield J.H..Hartree-Slater subshell photoionization cross-sections at 1254 and $1487 \mathrm{eV}$. J Electron SpectroscRelat Phenom. 1976, 8, 129-137.

23 K.A. Antimicrobial peptides: pore formers or metabolic inhibitors in bacteria? Nature Review Microbiol 2005, 3 (3), 238-250

24 I., Johannsmann D., Richter R.P. Hearing what you cannot see and visualizing what you hear: interpreting quartz crystal microbalance data from solvated interfaces. Analytical chemistry. 2011, 83 (23), 8838-8848.

25 ., Cuvier A.S., Valotteau C., Fadda G.C., Perez J., Karakas E., Abel S., Baccile N. Structure of BolaamphiphileSophorolipid Micelles Characterized with SAXS, SANS, and MD Simulations J. Phys. Chem. B. 2015 119(41), 13113-13133.

26 Paul S., Paul D., Basova T., Ray A. K. Studies of adsorption and viscoelastic properties of proteins onto liquid crystal phthalocyanine surface using quartz crystal microbalance with dissipation technique. The Journal of Physical Chemistry C. 2008, 112 (31), 11822-11830.

27 N., Bergaoui L., Landoulsi J., Lambert J.F., Boujday S. Silane layers on silicon surfaces : mechanism of interaction, stability and influence on protein adsorption. Langmuir. 2012, 28 (1), 656-665.

28 F., Ray A., Nordén B., Kasemo B. Characterization of PNA and DNA immobilization and subsequent hybridization with DNA using acoustic-shear-wave attenuation measurements. Langmuir. 2001, 17 (26), 8305 8312 .

29 L.K., Avena M.J. A simple model for adsorption kinetics at charged solid-liquid interfaces. Colloids and Surfaces A. 2001, 192 (1-3), 93-107.

30 Van Bogaert I.N., Saerens K., De Muynck C., Develter D., Soetaert W., Vandamme E.J. Microbial production and application of sophorolipids. Applied microbiology and biotechnology. 2007, 76 (1), 23-34.

31 N., Babonneau F., Hestin J., Pehau-Arnaudet G., Van Bogaert I. Unsual, pH-induced, self-assembly of sophorolipidbiosurfactant. ACS Nano, 2012, 6 (6), 4763-4776.

32 Torn L.H., Koopal L.K., de Keizer A., Lyklema J. Adsorption of non ionic surfactants on cellulose surfaces: adsorbed amounts and kinetics. Langmuir, 2005, 21 (17), 7768-7775.

33 C., Grady B. P., Striolo A. Experimental Studies on the Adsorption of Two Surfactants on SolidAqueous Interfaces: Adsorption Isotherms and Kinetics, Langmuir 2008, 24, 4806-4816

34 L., Blomberg E., Claesson P. M., Effect of Adsorbed Layer Surface Roughness on the QCM-D, Response: Focus on Trapped Water, Langmuir 2007, 23, 12436-12444

35 Yala J.-F., Thébault P., Héquet A., Humblot V., Pradier C.-M., Berjeaud J.-M..

36 G., Briggs D. The XPS of Polymers Database. Surface Spectra Publisher. ISBN 0-9537848-4-3.

37 R., Bouloussa O., Rondelez F. Evidence of a charge-density threshold for optimum efficiency of biocidal cationic surfaces. Microbiology. 2005, 151 (5), 1341-1348.

38 S.A., Leong S.S. Tethering antimicrobial peptides: current status and potential challenges. Biotechnol Adv. 2011, $29(1), 67-74$. 
39 S., Bantegnie A., Briand E., Marnet P.G., Salmain M., Pradier C.M. In-depth investigation of protein adsorption on gold surfaces: correlating the structure and density to the efficiency of the sensing layer. J Phys Chem B. 2008, 112 (21), 6708-6715.

40 O., Li Q., Farnsworth D., Gildersleeve G.C. Microarrays with Varying Carbohydrate Density Reveal Distinct Subpopulations of Serum Antibodies. J. Proteome Res., 2009, 8 (7), 3529-3538.

41 Wang X., Ramström O., Yan M. Glyconanomaterials: synthesis, characterization, and ligand presentation. Adv Mater. 2010, 22 (17), 1946-1953.

42 A., Raja Z., Casale S., Pradier C.-M., Foulon T., Ladram A., Humblot V. Temporin-Sha Peptides Grafted on Gold Surfaces Display Antibacterial Activity. Journal of Peptide Science 2014,20, 563-569.

43 A., Spasova D., Vasileva-Tonkova E., Galabova D. Effect of RML on cell surface of P aeruginosa. Microbiological Research. 2009, 164 (3), 297-303

44 Berglund N.A., Piggot T.J, Jefferies D., Sessions R.B., Bond P.J., Khalid S. Interaction Of the Antimicrobial Peptide Polymmyxin B1 with Both Membranes of E. coli:A Molecular Dynamics Study. PLoSComput Biol. 201511 (4), e1004180.Figure Caption 
Table 1. Bacterial strains and nutrient broths used

\begin{tabular}{|c|c|c|c|}
\hline & & Morphology & Broth \\
\hline \multirow[t]{4}{*}{ Gram+ } & Listeria ivanovii (Li4pVS2) & Bacilli $(0.4-0.5 \mu \mathrm{m} \times 0.5-2 \mu \mathrm{m})$ & Brain Heart Infusion (BHI) \\
\hline & $\begin{array}{l}\text { Staphylococcus epidermidis (IMIB } \\
\text { 567) }\end{array}$ & $\operatorname{Cocci}(0.8-1 \mu \mathrm{m})$ & Brain Heart Infusion (BHI) \\
\hline & Enterococcus faecalis (ATCC 29212) & Diplococci $(0.5-1 \mu \mathrm{m})$ & Mueller Hilton (MH) \\
\hline & $\begin{array}{l}\text { Streptococcus pyogenes (ATCC } \\
\text { 19615) }\end{array}$ & Chains of cocci $(0.5-1 \mu \mathrm{m})$ & Brain Heart Infusion (BHI) \\
\hline \multirow[t]{3}{*}{ Gram - } & Escherichia coli (ATCC 25922) & Bacilli $(0.5 \mu \mathrm{m} \times 1-3 \mu \mathrm{m})$ & Lysogeny Broth (LB) \\
\hline & Pseudomonas aeruginosa (PA 01) & Bacilli $(0.5-0.8 \mu \mathrm{m} \times 1.5-3 \mu \mathrm{m})$ & Mueller Hilton (MH) \\
\hline & Salmonella typhimurium (DT 193) & Bacilli $(0.7-1.5 \times 2-5 \mu \mathrm{m})$ & Mueller Hilton (MH) \\
\hline
\end{tabular}

Table 2. Estimated thicknesses of the organic layers (assumed to be homogeneous) formed on surfaces after immersion in sophorolipid solutions with different concentrations. The results presented here are the average of at least two measurements performed on two different samples in order to ensure reproducibility of the results. a variation of 1 to $2 \AA$ can be observed between similar samples.

\begin{tabular}{lccccc}
\hline & & \multicolumn{4}{c}{ Thickness (in $\AA$ ) and mean density $\left(10^{14}\right.$ molecules $\left./ \mathrm{cm}^{2}\right)$ of the } \\
& & $\underline{C}=0$ & $\underline{N}$ & $\underline{\text { Sollayer calculated from the signal of }}$ & density \\
\hline Control surface (cys) & & 3 & 3 & 3.8 \\
\hline Initial SL solution & $5 \mathrm{mg} \cdot \mathrm{L}^{-1}$ & 24 & 26 & 23 & 2.62 .9 \\
concentration & $50 \mathrm{mg} \cdot \mathrm{L}^{-1}$ & 27 & 30 & 26 & 2.6 \\
& $500 \mathrm{mg} \cdot \mathrm{L}^{-1}$ & 25 & 27 & 23 & \\
\hline
\end{tabular}



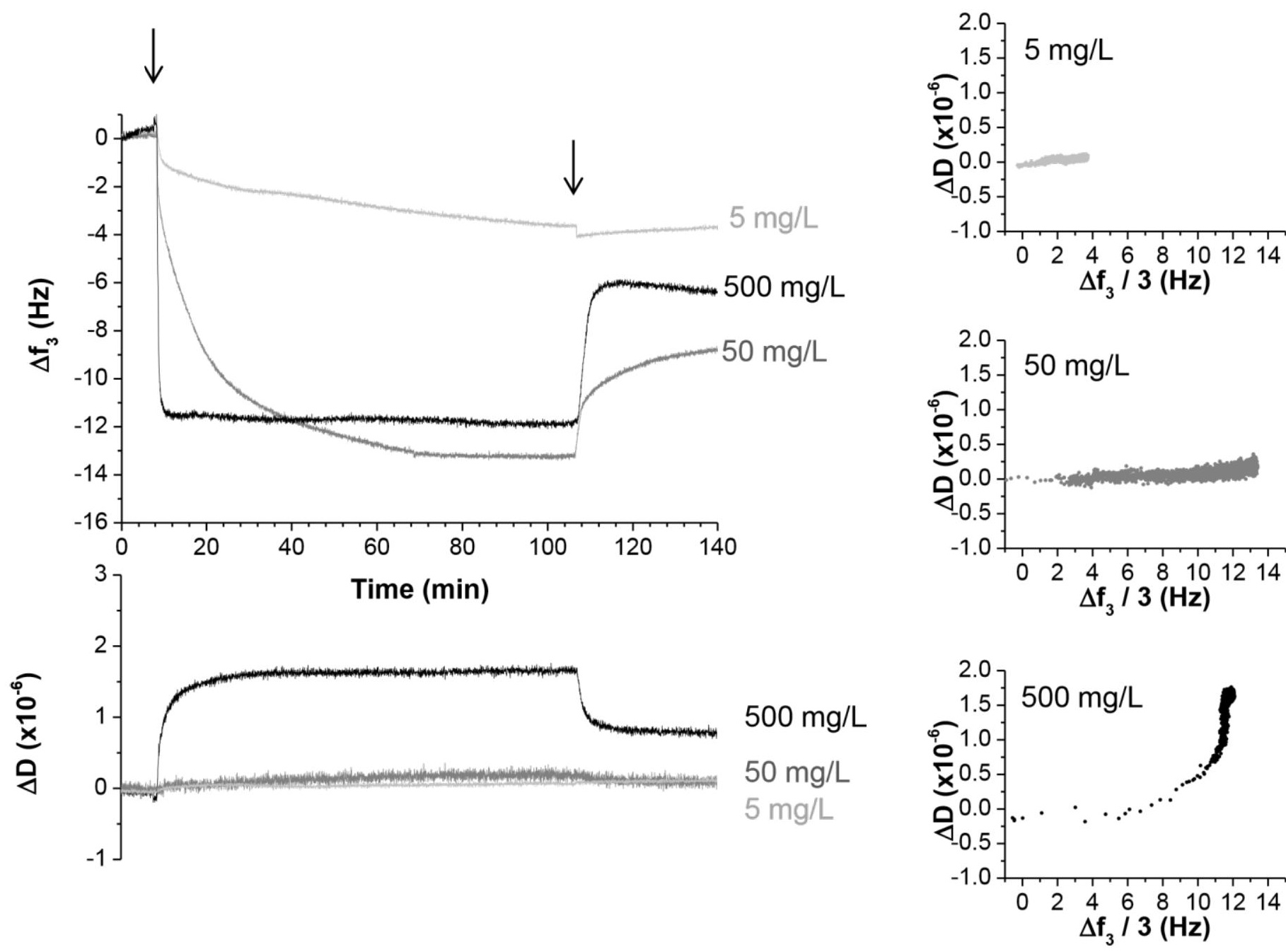

Figure 1. In situ monitoring of sophorolipid grafting at different concentrations ( $C=5,50$ and 500 mg. $\left.L^{-1}\right)$ by QCM-D. 
A
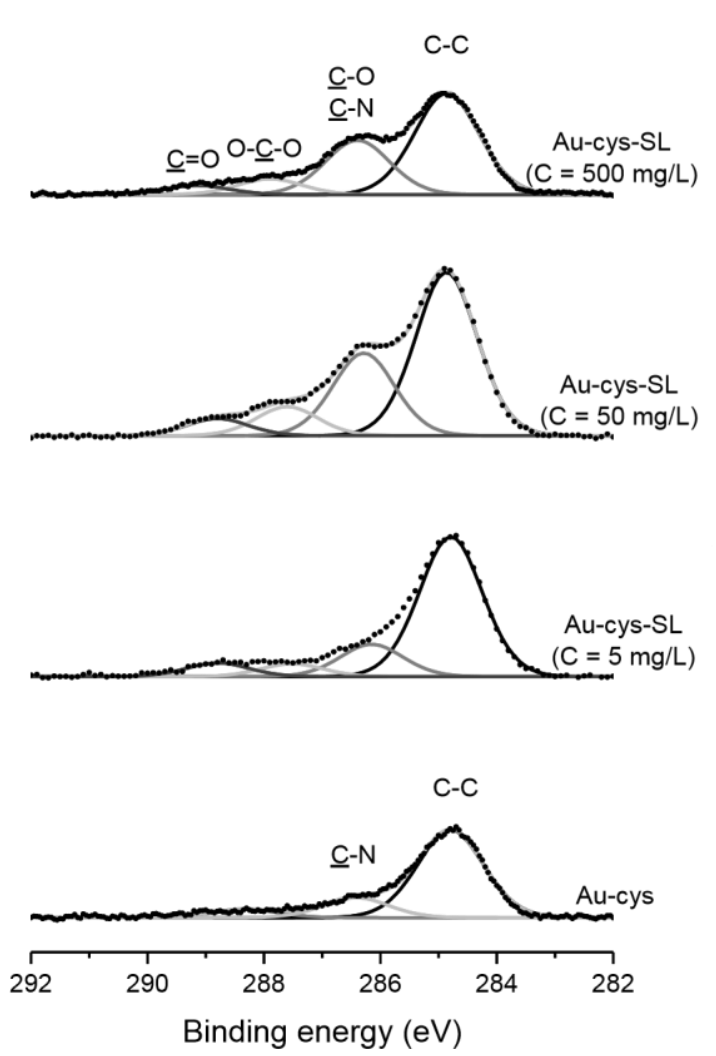

B
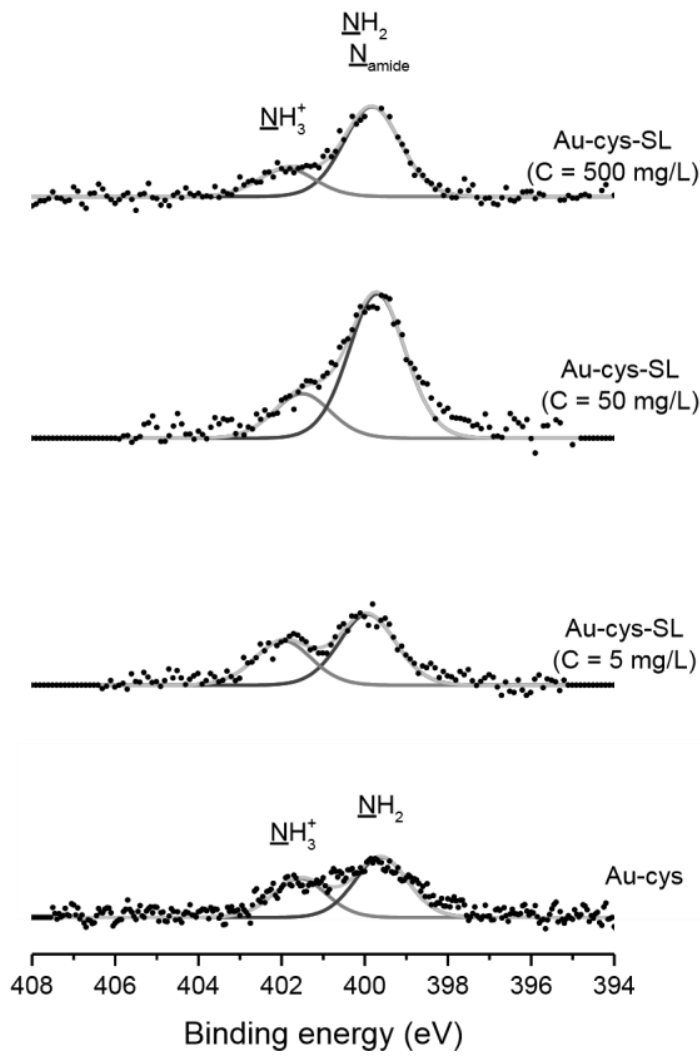

Figure 2. High resolution standardized XPS spectra of the C1s (A) and N1s (B) regions recorded on gold surfaces before (Au-cys) and after functionalization (Au-cys-SL) with sophorolipid solutions at varying concentrations $\left(C=5,50\right.$ or $\left.500 \mathrm{mg} \cdot \mathrm{L}^{-1}\right)$.

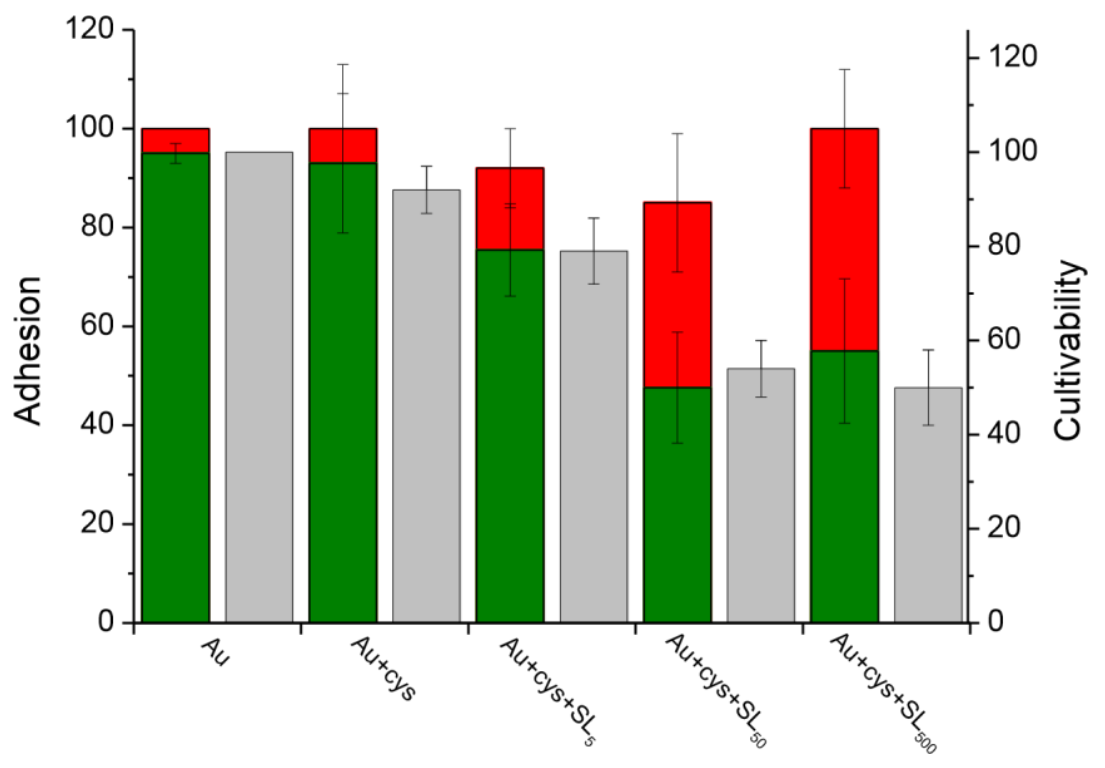


Figure 3. Adhesion (bicolor bars. left axis) and cultivability (grey bars. right axis) of Listeria ivanovii bacteria deposited on cysteamine-functionalized gold (Au-cys) and sophorolipid-functionalized gold (Au-cys-SL). The susbscript numbers indicate the initial concentration of sophorolipid grafting solutions $\left(5 \mathrm{mg} . \mathrm{L}^{-1} ; 50 \mathrm{mg} \cdot \mathrm{L}^{-1} ; 500 \mathrm{mg} . \mathrm{L}^{-1}\right)$. The results are relative to the same experiments performed on a bare gold substrate. The adhesive bars are colored according to the ratio of damaged (red) and intact (green) bacteria determined using the Live/Dead@ kit.

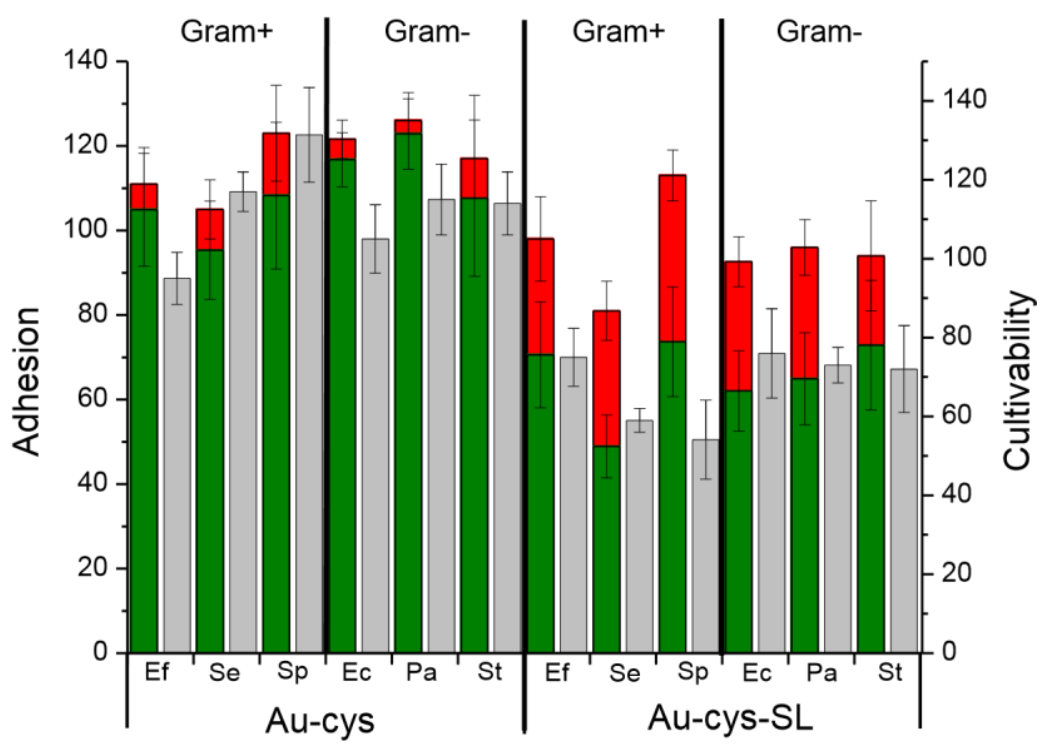

Figure 4. Adhesion (bicolor bars, left axis) and cultivability (grey bars, right axis) of various $\mathrm{Gram}^{+}\left(\mathrm{G}^{+}\right)$ and $\mathrm{Gram}^{-}\left(\mathrm{G}^{-}\right)$bacteria deposited on cysteamine-functionalized gold (Au-cys) and sophorolipidfunctionalized gold (Au-cys-SL). The results are relative to similar experiments performed on a bare gold substrate. The adhesive bars are colored according to the ratio of damaged (red) and intact (green) bacteria determined using the Live/Dead@ kit. The bacterial strains are indicated by their initials: $\mathrm{Ef}=$ Enterococcus faecalis $\left(\mathrm{G}^{+}\right) ; \mathrm{Se}=$ Staphylococcus epidermidis $\left(\mathrm{G}^{+}\right) ; \mathrm{Sp}=$ Streptococcus pyogenes $\left(\mathrm{G}^{+}\right) ; \mathrm{Li}=$ Listeria ivanovii $\left(\mathrm{G}^{+}\right)$; $\mathrm{Ec}=$ Escherichia coli $\left(\mathrm{G}^{-}\right) ; \mathrm{Pa}=$ Pseudomonas aeruginosa $\left(\mathrm{G}^{-}\right)$; $\mathrm{St}=$ Salmonella typhimurium $\left(\mathrm{G}^{-}\right)$. 


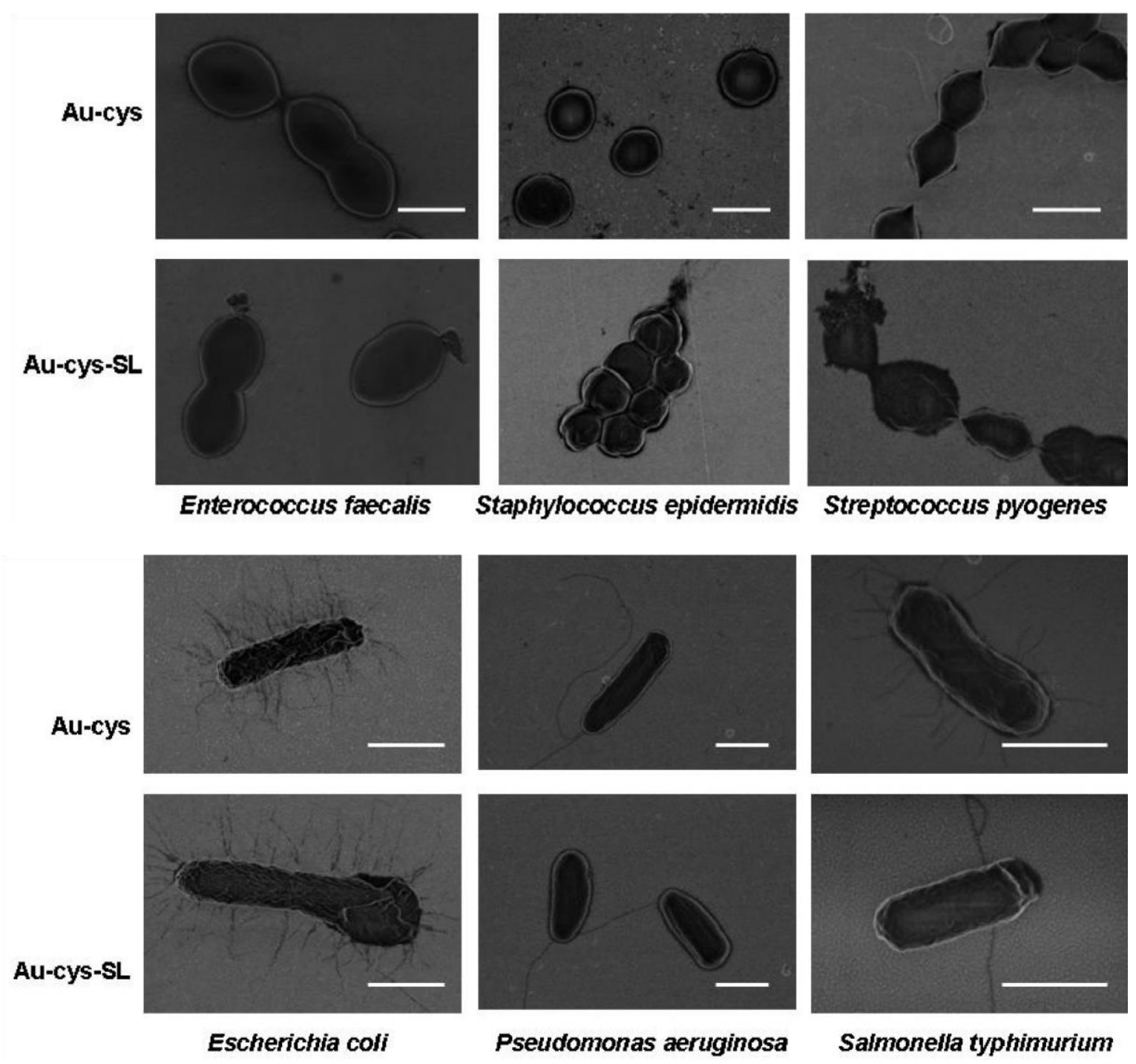

Figure 5. Ultrastructural morphology of $\mathrm{Gram}^{+}$(top) and $\mathrm{Gram}^{-}$(bottom) bacteria in contact with cysteamine-modified substrates (Au-cys) and SL-functionalized substrates (Au-cys-SL) observed by SEM. Scale bar $=1 \mu \mathrm{m}$ for all images. Arrows point at defects or damages on bacteria after contact with SL grafted-surfaces 